\title{
A IMAGEM DA ENFERMEIRA E DO ENFERMEIRO PERCEBIDA POR ALUNOS INGRESSANTES NO CURSO DE GRADUAÇÃO
}

\author{
Vera Lúcia Conceição de Gouveia Santos* \\ Aidê Ferreira Ferraz** \\ Maria José D'Elboux Diogo*** \\ Regina Marcia Cardoso de Souza*
}

\begin{abstract}
RESUMO - Estudo realizado com o objetivo geral de verificar a imagem da(o) enfermeira(o) percebida pelos alunos ingressantes no Curso de Graduação em Enfermagem de Duas Escolas da ".idade de São Paulo. Utilizou-se na metodologia o Diferencial Semântico de Osgood, validado por Lane no Brasil, além de um questionário que possibilitou uma melhor caracterização da imagem percebida pelos estudantes. Os resultados obtidos demonstraram que os alunos atribuíram significados diferentes para as palavras enfermeira e enfermeiro, somente para um dos fatores estudados (Agilidade), além de considerarem a imagem profissional como positiva, qualificada principalmente por características humanitárias $\Theta$ de competência.
\end{abstract}

ABSTRACT - The objetive of this approach is to verify the nurse's image perceived by primary students to nursing graduation course from two São Paulo Nursing Schools. The authors used the Osgood Semantic Differential modified and validated by LANE in Brazil. They used a questionary for better characterization of the perceived image. The data demonstrated that the students attributed different meanings to the words: male nurse and female nurse for one factor (Agility) only, and considered the professional image as positive with humanitarian and competence characteristcs.

\section{INTRODUÇÃO}

Vários estudos sobre imagem profissional da(o) enfermeira(o) têm sido realizados, visando identificar essa imagem junto ao público, junto a outros profissionais e entre os estudantes de enfermagem.

Segundo CABRAL \& NICK (1974), imagem é 0 produto da transposição psíquica de um objeto interno ou externo.

DORSH (1976) define imagem como a signifcação de idéia ou imà'gem que se forma de alguém, de uma coisa; forma uma finalidade complexa na qual entram atitudes, a informação que se tenha recebido, aspiraçōes e dese jos influrdos por um estado de opinião; cita ainda como sinônimos de imagem: fama, reputação, crédito e estereótipo.

Ao fazer-se uma retrospectiva histórica da enfermagem, pode-se observar que algumas mudanças relacionadas à imagem pública das(os) enfermeiras(os) têm ocorrido ao longo dos anos.

Nos primórdios, os cuidados de Enfermagem eram prestados tanto por prostitutas como pelas religiosas. As prostitutas eram aquelas mulheres que não serviam nem para o trabalho na indústria. Eram imorais, bêbadas e analfabetas, que prestavam cuidados aos doentes numa tentativa de se redimirem de seus pecados e alcançarem a salvação eterna. Durante muito tempo, este fato contribuiu para tornar vulgar a imagem das pessoas envolvidas com a Enfermagem. (ALMEIDA \& ROCHA, 1986).
Quanto às religiosas, tinham esta atividade como uma forma de se doarem às pessoas necessitadas, exercendo a caridade; a enfermagem era uma missão sagrada de prover um serviço de humanitarismo, que deveria ser desempenhada ao lado dos doentes, oportunidade em que estas deveriam não apenas tentar salvá-los fisicamente, mas também empenharem-se na salvação de suas almas. (CLARK, 1986)

CLARK (1986) coloca que neste periodo tentou-se corrigir os maus hábitos das(os) enfermeiras(os) e reforçar os bons, sendo o currículo das escolas voltado para o coração, a mente e o corpo, para produzir uma enfermeira com características de auto-disciplina, boa conduta e moral rígida, considerando-se ainda essenciais as boas maneiras e a boa aparência.

A partir dessa fase, a enfermeira passou a ser vista como um anjo de bondade, sempre pronta a ajudar a todos, não exigindo qualquer recompensa por seu árduo trabalho. Esta imagem tem persistido ainda atualmente, em grande parte do público, e ainda tem atrardo e influenciado pessoas a se dedicarem à Enfermagem, como uma forma de total doação ao ser humano, numa atitude solícita e abnegada de prestação de serviço aos necessitados.

KRATZ (1981) reviu o livro de Dra. Vassiliki Lanara ('Heroism as a nursing value') no qual consta que o centro da Enfermagem é o sofrimento

\footnotetext{
* Auxiliar de Ensino da Disciplina Enfermagem Médico-Cirúrgica da Escola de Enfermagem da USP.

* Auxiliar de Ensino da Disiciplina Fundamentos de Enfermagem da Escola de Enfermagem da Universidade Federal de Minas Gerais. ** Auxiliar de Ensino da Disciplina Enfermagem Médico-Cirúrgica da UNICAMP.
} 
e a dor, que são características da tragédia de vida do homem, e o heró́smo é considerado ainda como uma virtude, tendo o herói as características de bravura, firmeza e grandeza de espírito. LANARA comentada por KRATZ (1981), associou a Enfermagem com cinco personagens da tragédia grega e da Bíblia, atribuindo à profissão características como: responsabilidade, respeito pela dignidade do homem, sacrifício, herósmo no sof rimento (a enfermeira identifica-se com o sof rimento dos pacientes, e encontra a essência da Enfermagem) e ainda, a compaixão e o amor. Novamente vê-se salientado o aspecto da dedicação total à profissão e sendo questionada por esta autora, a necessidade desse heroísmo, ou se apenas confiança, compromisso e verdade já não seriam atos de heró́smo.

Vê-se assim, que a imagem da Enfermeira ficou durante muito tempo situada em dois extremos: de "prostituta" e "anjo de bondade", sendo que ambas foram muito fortes e marcantes, tanto que, até hoje tem-se observado a presença de resquícios destes dois extremos influenciando a imagem que muitas pessoas têm das enfermeiras.

A atual imagem pública das(os) enfermeiras(os) tem representado um grande problema para estes profissionais, pois tem-se notado no contato diário e contínuo com os pacientes e seus familiares, que a maioria deles tem uma imagem negativa das(os) enfermeiras(os), a qual nem sempre corresponde à realidade e que é corroborada pelos meios de comunicação de massa, que exercem grande poder sobre a população em geral. (HOTT, 1984)

Em conseqüência dessa imagem distorcida, notamos que ocorre uma certa desvalorização do trabalho destes profissionais e um baixo "status" em relação a outras profissões da mesma área.

Segundo KALISCH \& KALISCH, apud SNOW-ANTLE (1984), o estereótipo pode ser prejudicial para uma profissão, pois as pessoas crêem no estereótipo e não vêem a realidade. $O$ estereótipo distorce o conceito da imagem que o público tem da(o) enfermeira(o), afeta a decisão de política de alocação de recursos para a profissāo e priva os consumidores de conhecer o vital serviço promovido pelas(os) enfermeiras(os).

PARA TIFFANY (1981), o desenvolvimento do trabalho da maioria das enfermeiras não tem apresentado as características de um serviço profissional e que isto, aliado ao amplo emprego de rotinas e à delegação das atribuições das enfermeiras, têm sido alguns dos principais fatores de abalos ao profissionalismo na enfermagem, favorecendo as deformações da imagem profissional da(o) enfermeira(o).

Porém, o problema da imagem profissional não é tão restrito a ponto de ser possível analisá-lo isoladamente. Segundo SOUSA et alii (1986), o poder, a imagem e o espaço profissional estão diretamete relacionados e parecem constituir fatores preponderantes no contexto social de todas as profissōes. Nota- -se que poder, imagem e espaço são realmente questões cruciais para a Enfermagem, para as quais urge que se encontrem soluções.

A projeção de uma imagem positiva e a ocupação de um espaço profissional são buscados pela maioria das pessoas, e pode-se ainda dizer que são aspectos essenciais à auto-realização. (SOUSA, 1986)

SOUSA et alii (1986) e CLARK (1986), colocam que a imagem pública do enfermeiro não tem sofrido modificações significativas ao longo do tempo e que este profissional tem sido caracterizado como obediente, permissivo, conformista, flexível, bom e ativo, porém fraco, e que essa imagem sugere que $\mathrm{a}(\mathrm{o})$ enfermeira(o) não é capaz de assumir uma posição de independência e autoridade. Sendo assim, a assistência prestada por este é desvalonizada quando desvinculada do tratamento médico, que é um fator limitante da atuação da(o) enfermeira(o). Para SOUSA et alii (1986), a perda de poder e de espaço, $\mathrm{e}$ as distorções da imagem profissional $\mathrm{da}(0)$ enfermeira(o), trazem como conseqüência, sentimentos de frustração, insatisfação e amargura, falta de reconhecimento da autonomia profissional: baixa remuneração e falta de "status"; queda do nível de ensino nas escolas de enfermagem e falta de participação na política do sistema de saúde. Todas essas conseqüências são também percebidas pelos doentes, por meio da assistência deficiente que recebem. Estes também se sentem frustrados e insatisf eitos, o que pode reforçar uma imagem profissional negativa da(o) enfermeira(o), muitas vezes já incorporada pelo cliente.

Tais colocações evidencias a relevância, a abrangência e a complexidade da questão da imagem profissional, principalmente no caso da Enfermagem, que vem se ressentindo dia a dia das conseqüências advindas da projeção de uma imagem deformada.

Segundo CLARK (1986), é necessário que as(os) enfermeiras(os) examinem a origem de seus sentimentos sobre si mesmas(os) e sua profissāo, aliviando toda a bagagem emocional negativa, tomando-se mais ativa(os) e positivas(os) ao invés de alimentarem auto-compaixão. Desta forma, estarão contribuindo para mudanças efetivas na imagem profissional.

O problema da imagem da(0) enfermeira(o) diz respeito a todos os enfermeiros e, ao mesmo tempo, a cada um deles em particular, pois a imagem do grupo é reflexo direto da imagem profissional individual. (MARSH, 1983; SNOW-ANTLE, 1984) Cabe a cada enfermeira(o), individualmente, a responsabilidade da projeção de uma imagem profissional positiva para que a imagem global possa, conseqüentemente, ser transformada.

KUENZER (1985) ao questionar algumas crianças em idade escolàr a respeito da escolha profissional, constatou que elevado número destas manifestou interesse pela enfermagem como profissão, demonstrando terem uma imagem do enfermeiro como al- 
guém que cuida da saúde dos outros.

Ao conversar com estudantes em fase inicial do curso de Enfermagem, é freqüente ouvir-se que grande parte deste optou pela enfermagem por gostarem de ajudar os outros e por ser esta uma profissão em que é possível servir à humanidade (WATSON, 1982). Entretanto, poucas vezes tem-se ouvido que alguém tenha escolhido a enfermagem porque gostaria de ser um profissional tão competente e bem sucedido quanto algum enfermeiro que tenha conhecido (HAMMER \& TUFTS, 1985). Isto sugere que os enfermeiros em geral, não têm sido profissionais-modelos a ponto de influenciarem e atraírem os estudantes para a profissão.

Para que se processem mudanças radicais e duradoura na imagem profissional da(o) enfermeira(o), há que se percorrer um longo caminho, a começar pelas mudanças na auto-imagem e auto-conceito.

De acordo com HAMMER \& TUFTS (1985) a auto-imagem da(o) enfermeira(o) é uma responsabilidade da educação na Enfermagem. As autoras acreditam que é possível observarem-se progressos no que se refere à elevação da imagem profissional $\mathrm{da}(0)$ enfermeira(0), mas que uma maior elevação dessa imagem precisa começar na fase de formação da(o) enfermeira(o), quando os educadores devem estimular o desenvolvimento de um auto-conceito positivo, incluindo a auto-imagem e a auto-estima. Segundo estas autoras, o auto-conceito pode ser. aprendido. Ele é derivado de todas as experiências de vida, de sucessos, falhas e humilhações; destas experiências o indivíduo extrai o seu auto-retrato e desenvolve um conjunto de atitudes coerentes com este. $O$ indivíduo então, comporta-se conforme estas atitudes e o retrato que tem de si mesmo.

FRANCIS \& MUNJAS, apud HAMMER \& TUFTS (1985), afirmam que os indivíduos com um auto-conceito positivo estão mais aptos a realizarem suas aspirações, e são geralmente mais saudáveis e mais produtivos do que aqueles com um auto-conceito mais negativo. Isto nos conduz a uma questão: se a imagem da(o) enfermeira(o) é um assunto importante para a profissão, porque não discuti-lo e trabalha-lo junto aos estudantes de Enfermagem? Ou devem as escolas deixar o aluno à deriva, formando a sua imagem da profissão à medida que vai sendo exposto à prática?

HAMMER \& TUFTS (1985), consideram que as Escolas de Enfermagem devem ser as propulsoras para transformar a imagem da profissão em muito positiva e de forma permanente, começando quando o profissional é ainda estudante. Para essas autoras, alguns educadores transmitem aos alunos sentimentos de inadequação, falta de confiança e insegurança na tomada de decisões, que ainda têm caracterizado muitos enfermeiros, e que estes sentimentos contribuem para a falta básica de uma auto-estima e para uma pobre imagem profissional, pois a falta de auto-estima é uma força poderosamente inibidora.
BAKER \& MORGAN (1985) colocam que geralmente os supervisores estão tão ocupados que não se preocupam com a imagem profissional e que é importante construir uma imagem profissional real, pois uma imagem positiva, porém falsa, pode gerar uma vitória passageira e também falsa.

A importância do papel das Escolas de Enfermagem na projeção da imagem da(o) enfermeira(o) foi solicitada no XIX Congresso Brasileiro de Enfermagem, 1966, onde uma das recomendações foi a de que as diretorias das escolas e o corpo docente priorizassem uma campanha de divulgação sobre a profissão, procurando criar uma nova imagem da(o) enfermeira(o) (CASTRO et alii, 1974).

Segundo' KALISCH \& KALISCH, apud SNOW-ANTLE (1984) o estereótipo da(o) enfermeira(o) mantido pela sociedade, afeta a qualidade de pessoas ingressantes na profissão. Observa-se esta ocorrência na maioria das Escolas de Enfermagem, onde os alunos ingressantes nem sempre têm a Enfermagem como primeira opção e vê-se ainda uma redução do número de pessoas que procuram cursar Enfermagem, ficando muitas vagas nos cursos sem serem preenchidas. Isto parece significar desinteresse dos estudantes em ingressarem na profissão, o que por sua vez pode ser resultado de uma imagem profissional estereotipada.

Partindo-se da premissa de que a projeção de uma imagem negativa representa um entrave para o desenvolvimento da profissão e para sua maior valorização por parte da sociodade, sentiu-se a necessidade de se verificar junto aos alunos ingressantes no curso de graduação em Enfermagem, a imagem por eles atribuída à(o) enfermeira(o) e a influência desta na escolha profissional desses estudantes.

\section{OBJETIVOS}

Este estudo tem como objetivos:

2.1 verificar a imagem do enfermeiro e da enfermeira percebida pelos alunos ingressantes no curso de graduação de duas Escolas de Enfermagem da Cidade de São Paulo, quanto a:

- características atriburdas a(o) enfermeira(o);

- atividades exercidas pela(o) enfermeira(0);

- locais de trabalho da(o) enfermeira(o);

2.2 verificar os fatores que influenciaram na formação da imagem da(o) enfermeira(o) percebida por esses estudantes;

2.3 verificar a influência da imagem da(o) enfermeira(o) na escolha profissional desses estudantes.

\section{METODOLOGIA}

\subsection{População e Amostra}

A população do estudo foi constiturda por alunos ingressantes no Curso de Graduação em Enfer- 
magem de duas Escolas da Cidade de São Paulo, sendo uma particular e uma governamental, designadas durante o estudo como escolas A e B respectivamente.

Para determinar o número de alunos que compôs a amostra, optou-se pelo equivalente a $20 \%$ das vagas para o 1. semestre do curso de Graduação dessas escolas. Sua escolha, recaiu sobre os primeiros estudantes da lista de freqüência que se encontravam na sala de aula, no dia da coleta de dados e que concordarem em participar do estudo. Os alunos repetentes, foram exclú́dos da amostra.

3.2 Instrumentos de coleta de dados:

A coleta de dados foi feita utilizando-se:

- escalas bipolares do Diferencial Semântico (D.S.) de OSGOOD, em relação às palavras enfermeira e enfermeiro;

- um questionário com questōes abertas acerca das percepçōes dos alunos quanto à imagem, características, atividades e locais de trabalho do enfermeiro e sobre a influência da imagem do enfermeiro na escolha profissional do aluno. Constou também de uma questão fechada sobre as interferências na formação da imagem do enfermeiro.

O Diferencial Semântico (D.S.) desenvolvido por OSGOOD et alii (1956), e aplicado em diferentes culturas, tem-se mostrado bastante eficaz para o estudo da comunicação, Já que consiste em uma técnica para a medida do significado das palavras. Esses estudos são basicamente de psico-lingürstica. A premissa básica do D.S. é que a linguagem, características das idéias, objetos e entidades são comunicados por adjetivos. Assim, já que a função básica da linguagem é assumida como para a comunicação do significado, então essa linguagem também poderia ser usada para diferenciar os conceitos e medir seus significados (AUSTIN et alii, 1985; BALDIN, 1977; FISHBEIN \& AJZEN, 1975; HORTA \& KAMNEBLEY, 1975; LANE, 1982; 1972).

A estrutura de um "Espaço Semântico" assim proposto, em caráter universal, seria definida por 3 dimensões: Valorativa, de Potência e de Atividade, representadas respectivamente, por adjetivos como bom-mau, forte-fraco, e rápido-lento, sugerindo uma relação com os sistemas emocional, energético e de ação (HORTA \& KAMNEBLEY, 1975; LANE, 1982).

No entanto, se de um lado a estrutura semântica se generaliza transculturalmente, os adjetivos saturados que compõem essas dimensões ou fatores, diferem de cultura para cultura (LANE, 1982).

A partir dá, LANE (1982), aplicando o método no Brasil, validou-o para a língua portuguesa através da definição dos adjetivos bipolares, que constituíram não 3 mas 7 fatores, que desta forma dimensionam ou caracterizam o "Espaço Semântico" em nossa cultura (HORTA \& KAMNEBLEY, 1975; LANE, 1982; 1972).
A técnica do D.S. consiste em criar diversos adjetivos bipolares para a qualificação de determinado conceito, para que o respondente possa graduar esses conceitos dentro de uma escala de 7 pontos, podendo assim indicar a direção (positiva ou negativa) e a intensidade $(+3$ a -3$)$ de cada julgamento (AUSTIN et alii, 1985; BARDIN, 1977; FISHBEIN \& AJZEN, 1975; HORTA \& KAMNEBLEY, 1975; LANE, 1982; 1972).

Neste estudo foram utilizados os seguintes adjetivos bipolares, selecionados dentre aqueles enquadrados nos 7 fatores validados por LANE (1982):

FATOR II (VALORATIVO)

- bom-mau humano-desumano delicado-grosseiro desejável-indesejável inteligente-burro calmo-inquieto seguro-perigoso limpo-sujo saudável-doentio

FATOR II (POTÊNCIA)

- poderoso-fraco profundo-superficial

FATOR III (ESTABILIDADE)

- perfeito-imperfeito duradouro-passageiro estável-instável

FATOR IV (AGILIDADE)

- quente-frio rápido-lento

FATOR V (SIMPLICIDADE)

- fácil-difícil simples-complicado

FATOR VI (DIMENSÃO)

- grosso-fino pesado-leve

FATOR VII (UTILIDADE)

- indispensável-dispensável necessário-desnecessário útil-inútil

A localização dos adjetivos no instrumento foi feita a partir de um sorteio.

3.3. Procedimento para a coleta de dados:

A coleta de dados foi realizada em abril de 1987 , após a autorização obtida da Administração das 2 escolas que compuseram este estudo.

Estabeleu-se então, uma data especifica para a coleta da dados, conforme a possibilidae dos professores dessas escolas de concederem um tempo de suas atividades junto aos alunos.

Simultaneamente, levantou-se o número de vagas disponíveis para o 1. ${ }^{\circ}$ semestre do Curso de Graduação em Enfermagem, determinando-se a partir dar o número de alunos de cada escola que iriam fazer parte do estudo. Cita-se a seguir, o número de vagas disponíveis para o ingresso ao 1 . semestre e o número de alunos participantes da amostra, em cada 
uma das duas escolas:

Escola A - 100 vagas -20 indivíduos participantes da amostra (20\%)

Escola B - 80 vagas - 16 indivíduos participantes da amostra (20\%)

Efetuou-se então, a coleta de dados, que se constituiu primeiramente da aplicação das escalas bipolares do D.S., seguida imediatamente da aplicação do questionário.

No momento da aplicação do primeiro instrumento, foi realizada uma orientação prévia, na qual se utilizou o quadro negro para transcrever o exemplo de uma escala bipolar ali constante. Ao término desta orientação, esclareceram-se as dúvidas existentes, e só então permitiu-se aos estudantes a visualização do conteúdo deste instrumento.

Posteriormente à devolução de todos os instrumentos utilizados nesta 1. fase, foram distriburdos os questionários, sobre os quais não houve esclarecimentos adicionais.

Durante a aplicação de cada u m dos instrumentos, foram cronometrados os tempos gastos pelos alunos para respondê-los.

Cabe ressaltar que, precedendo à coleta de dados propriamente dita, foi realizado um pré-teste do questionário, com 10 alunos do $2^{\circ}$. ano da Escola B, surgindo dar, a necessidade de pequenas modificações para maior compreensāo.

\subsection{Tratamento dos dados}

Os dados obtidos através dos questionários estão apresentados em tabelas com freqüências absolutas e relativas.

Já os dados obtidos através das escalas de adjetivos bipolares, foram submetidos aos seguintes tratamentos:

3.4.1 Média por fator e por palavra, em cada Escola.

A partir dos valores atribuídos nas escalas bipolares (de $-3 \mathrm{a}+3)$, obteve-se o resultado da soma algébrica de cada fator, para as palavras enfermeira e enfermeiro, para cada indivíduo inicialmente e posteriormente para cada grupo. Os resultados obtidos por grupo, foi feita a média de valores obtidos em cada fator, em cada escola e para cada palavra, considerando-se para isto, o número de escalas bipolares por fator e o número de indivíduos por grupos.

Exemplificando, na escola A havia 20 alunos no grupo e 9 escalas bipolares para o fator I. O valor obtido na soma algébrica do fator I, na escola A, para a palavra enfermeira foi +367 . Assim sendo, a média (M) para o fator I, na escola A, para palavra enfermeira é $+2,04$.

$$
M=\frac{+367}{20 \times 9}=+2,04
$$

\subsection{2 Índice de Contradição Interna (CI)}

O Índice da Contradição Interna, segundo descrito por LANE $(1982 ; 1972)$, foi feito por fator e por grupo de alunos, para cada palavra a partir da soma aritmética (Polarização Individual + PI) e da soma algébrica (Polarização grupal = PG) dos valores atribuídos pelos alunos nas escalas bipolares. Para obter-se os valores mostrados.

\subsubsection{Prova U de Mann-Whitney}

Com o objetivo de verificar se os diferentes grupos (escola, sexo) provinham ou não da mesma população, aplicou-se a Prova U de Mann-Whitney. Preferiu-se um teste não paramétrico no lugar de comparações entre médias pela prova " $t$ " ou pela análise de variância para não se depender da admissão de suposta normalidade nas distribuições ou da suposta igualdade de variâncias.

As provas foram realizadas bilateralmente, ao nível de significância de $5 \%$. Os valores critícos foram retirados da tabela publicada por SIEGEL (1975), à pág. 307.

\section{APRESENTAÇÃo E DISCUSSÃo dOS RE- SULTADOS}

A amostra do presente estudo foi composta de 36 estudantes que atenderam aos critérios previamente estabelecidos, sendo 20 pertencentes à Escola A e 16 à Escola B. De todos os alunos, somente um, da Escola A, era do sexo masculino. quanto à idade, houve diferenças importantes entre as duas Escolas. $\mathrm{Na}$ Escola A, os alunos distribuíram-se com maior freqüência e de forma eqüitativa nas faixas de 17 a 20 anos e 21 a 25 anos, havendo, no entanto, 4 sujeitos com mais de 31 anos. Já na Escola B, a maior parte dos alunos estava inserida na faixa de 17 a 20 anos e nenhum dos outros ultrapassou a idade de 25 anos.

Quanto à apresentação e análise dos demais resultados, foram desenvolvidos em duas fases, através dos dados obtidos a partir das escalas bipolares do Diferencial Semântico e dos questionários com questōes abertas e fechadas, já se estabelecendo o relacionamento desses dados durante as discussões

4.1 Dados obtidos através do D.S.:

Os alunos responderam às escalas bipolares do D.S. num tempo médio de 8 minutos, sendo que para a escola A, este período foi de 3 a 12 minutos e para a Escola B, de 7 a 11 minutos.

Para a análise dos dados obtidos através do D.S., utilizou-se a forma reduzida dos adjetivos bipolares preconizada por LANE (1982), para cada fator: bom-mau (fator I); forte-fraco (fator II); estável-instável (fator III); rápido-lento (fator IV); simples-complicado (fator V); grande-pequeno (fator VI) e útil-inútil (fator VII).

Os valores atriburdos pelos estudantes nas escalas de adjetivos bipolares que compunham cada um dos sete fatores estudados, permitiram a obtenção das médias apresentadas no Quadro 1. 


\section{QUADRO 1}

Médias dos fatores obtidos para os significados

das palavras enfermeira e enfermeiro, dos estudantes de duas

Escolas da Cidade de São Paulo, 1987

\begin{tabular}{l|c|c|c|c}
\hline & \multicolumn{2}{|c|}{ ENFERMEIRA } & \multicolumn{2}{c}{ ENFERMEIRO } \\
\hline \multicolumn{1}{c|}{ FATORES } & $\begin{array}{c}\text { ESCOLA } \\
\text { A }\end{array}$ & $\begin{array}{c}\text { ESCOLA } \\
\text { B }\end{array}$ & $\begin{array}{c}\text { ESCOLA } \\
\text { A }\end{array}$ & $\begin{array}{c}\text { ESCOLA } \\
\text { B }\end{array}$ \\
\hline VALORATIVO (I) & $+2,04$ & $+2,46$ & $+2,15$ & $+2,43$ \\
POTENCIA (II) & $+1,45$ & $+1,53$ & $+1,50$ & $+1,34$ \\
ESTABILIDADE (III) & $+1,18$ & $+1,56$ & $+1,52$ & $+1,52$ \\
AGILIDADE (IV) & $+1,17$ & $+1,75$ & $+1,02$ & $+1,56$ \\
SIMPLICIDADE (V) & $+0,60$ & $+1,03$ & $+0,80$ & $+0,72$ \\
DIMENSÃO (VI) & $+1,35$ & $+1,78$ & $+1,42$ & $+1,44$ \\
UTILIDADE (VI) & $+2,27$ & $+2,67$ & $+1,90$ & $+2,64$ \\
\hline
\end{tabular}

Os dados do Quadro 1 mostram que as palavras enfermeira e enfermeiro obtiveram pontuaçōes positivas para todos os sete fatores em ambas as Escolas, sendo que os maiores valores incidiram nos fatores I (Valorativo) e VII (Utilidade). De maneira oposta, o fator V (Simplicidade), englobou os menores índices para as duas palavras, nas duas Escolas.

A direção positiva das respostas dos estudantes, refletida nas médias obtidas, indica que a enfermeira e o enfermeiro são considerados por eles, em maior ou menor escala, como bons, fortes, estáveis, rápidos, simples, grandes e úteis.

Ao submeterem-se os dados (que, ao final, resultaram nas médias observadas no Quadro 1), à aplicação da Prova U de Mann-Whitney, objetivou-se verificar a existência de diferenças significativas ao nível de $5 \%$, entre os dois grupos de alunos, quanto às palavras estudadas e, entre as palavras, independentemente do grupo de origem (SIEGEL, 1975). Os dados obtidos revelam que não houve diferença significativa entre o significado das palavras enf emeira e enfermeiro, quanto a qualquer um dos fatores estudados, quando comparados entre as duas Escolas. Já, com relação ao significado dessas palavras, independentemente da Escola de origem, houve diferença significativa, ao nfvel de 5\%, para a palavra enfermeiro, em relação ao fator IV (Agilidade) parecendo então, que o enfermeiro é considerado menos ágil que a enfermeira.

Índice de Contradição Interna (CI)

Após a aplicação do índice de CI, verificou-se que a Escola A, apresentou maiores índices de CI em relação à Escola $\mathrm{B}$, para todos os fatores, para as duas palavras estudadas, à exceção do fator $\mathrm{V}$ (Simplicidade), para a palavra enfermeiro.

Segundo LANE (1982), um maior índice de CI pode indicar:

- dois ou mais significados diferentes atriburdos à palavra;
- a palavra ser desconhecida e os indivíduos darem respostas aleatórias; e

- a palavra pode, de fato, ser afetivamente controvertida ou conflitual para nossos sujeitos.

A partir dessas indicaçōes e considerando-se que as palavras enfermeiro e enfermeira não propiciam, a nosso ver, significado ambrguo e muito menos desconhecido, pode-se dizer que os estudantes da Escola A têm significados controversos ou conflitantes para as palavras estudadas.

Já a Escola B, apresentou estereotipia de respostas nos fatores I (Valorativo), IV (Agilidade), e VI (Dimensão) para a palavra enfermeira. Para ofator V (Simplicidade), a mesma Escola apresentou 0 maior índice de CI, em relação aos demais fatores, para as duas palavras estudadas.

Em trabalho desenvolvido por AUSTIN et alii (1985), utilizando o Diferencial Semântico para o significado da palavra "nurse", em 30 culturas diferentes, foram obtidas para o Brasil, as seguintes pontuaçōes para os fatores estabelecidos por OSGOOD: Valorativo (Evaluation) $=+0,46$; Potência $($ Potency) $=-0,90$ e Atividade (Activity) $=$ $-0,37$.

Embora utilizando, no presente estudo, os $7 \mathrm{fa}$ tores desmembrados e validados para o Brasil por LANE (1982; 1972), a partir dos 3 fatores de OSGOOD, verificam-se diferenças importantes nos resultados obtidos, em relação aos de AUSTIN et alii (1985), que encontraram índices próximos à neutralidade. Destes fatores, somente o Valorativo assemelhou-se ao encontrado neste trabalho (Quadro 1), em relação à direção das respostas (positiva), embora em menor intensidade. Desta forma, a população estudada por aqueles autores considerou "nurse" como boa, porém fraca e passiva. Vale ressaltar que esses achados foram alcançados de maneira semelhante, nas 30 culturas pesquisadas.

As diferenças encontradas podem ser justifica- 
das inicialmente, por uma mudança na imagem do enfermeiro nos últimos 12 anos, já que AUSTIN et alii (1985) utilizaram para seus estudos, os dados contidos no Atlas of Affective Meanings de OSGOOD et alii de 1975. Corroborando essa assertiva, existem alguns autores tais como MCFARLANE (1985) e SNOW-ANTLE (1984), que consideram estarem ocorrendo, lentamente, transformaçōes positivas na imagem pública do enfermeiro. Além disso, deve-se levar em conta que, diferentemente da população estudada por AUSTIN et alii (1985), a deste estudo foi composta de estudantes ingressantes, que foram atraídos por algum aspecto da profissão, que, de alguma forma, compōe a imagem pública do enfermeiro.

4.2 Dados obtidos através dos Questionários:

Os alunos responderam aos questionários num tempo médio de 14,75 minutos, sendo que para a Escola A, este perfodo foi de 6 a 28 minutos e para a Escola B, de 8 a 17 minutos.

As respostas dos estudantes das duas Escolas de Enfermagem da Cidade de São Paulo, foram analisadas e classificadas dentro de agrupamentos que indicaram predicados pessoais e aspectos da profissão.

Os resultados indicam que a imagem do enfermeiro atriburda pelos estudantes foi caracterizada fundamentalmente por predicados pessoais, já que a incidência de respostas neste item foi de $91,75 \%$, distribuídos eqüitativamente nas escolas A e B $(45,36 \%$ e $46,39 \%$ respectivamente).

Analisando-se os predicados pessoais apontados pelos alunos para o delineamento da imagem do enfermeiro, observa-se que as características humanitárias foram predominantes nas respostas dos estudantes $(32,99 \%)$, também de maneira similar nas duas escolas $(17,53 \%$ e $15,46 \%$ respectivamente).

Deve-se ressaltar ainda que a grande maioria das respostas caracterizou predicados pessoais positivos para qualificação da imagem do enfermeiro, sendo que somente $6,18 \%$ das respostas indicaram predicados negativos.

De maneira semelhante, CASTRO et alii (1974), em estudo da imagem do enfermeiro percebida pelos estudantes do 1. e 7 ${ }^{\circ}$ semestres do Curso de Graduação em Enfermagem, encontraram em seus resultados respostas que caracterizaram uma imagem positiva, onde as funçōes, aspiraçōes e valores atribuídos ao enfermeiro refletiram profundo comprometimento com a profissão.

Quanto às respostas que indicaram aspectos da profissão $(8,25 \%)$, a ênfase foi dada às atividades desenvolvidas pelo enfermeiro (7,22\%). Considerando-se que a Enfermagem é uma profissão essencialmente prática, pode-se dizer que este índice $(7,22 \%)$ é inferior ao esperado, quando comparado ao índice referente às características pessoais $(91,75 \%)$.
Os 36 estudantes que compuseram este estudo, atribuíram ao enfermeiro um total de 127 características, perfazendo uma média de 3,5 respostas por estudante. Devemos esclarecer que 4 itens foram excluídos do total de respostas obtidas, por indicarem atividades que o enfermeiro desempenha.

As características mais freqüentemente apontadas pelos alunos foram: humanitárias $(37,79 \%)$; de competência $(27,56 \%)$; de tranqüilidade e de segurança (ambas com 10,24\%), enquanto que o predicado menos indicado foi o de simplicidade o que coincidiu com aquele que alcançou menor valor nas escalas bipolares de OSGOOD (Quadro 1), parecendo não ser, portanto, uma característica muito valorizada para o enfermeiro.

Segundo CLARK (1986), desde Nightingale o preparo do enfermeiro tem sido voltado para a "missão sagrada" de promover um "serviço para a humanidade"”.

Essa missão da Enfermagem aparece no livro de LANARA e é comentada por KRATZ (1981), em que aquela autora a associa com o espírito de heróismo apresentado por personagens bíblicos e da tragédia grega, reunindo características de responsabilidade (Prometeus), respeito pela dignidade humana (Antígone), sacrifício (Ifigênia), sofrimento (J6) e bondade (o bom samaritano).

SNOW-ANTLE (1984), em seu trabalho sobre a opinião pública da imagem da enfermeira, encontrou como qualificaçōes positivas mencionadas pela população: cuidadora $(90 \%)$, responsável $(88 \%)$, conhecedora (84\%) e eficiente (82\%). Quanto às qualificações negativas, ficaram em torno de $8 \%$.

Analisando-se:

- os dados apresentados no Quadro 1, em que as palaviras: enfermeira e enfermeiro foram revestidas de um significados positivo e onde o fator valorativo (bom-mau) sobressaiu-se, nas duas escolas;

- as características positivas atribuídas à imagem e ao próprio enfermeiro onde houve predominio das humanitárias $(32,98 \%$ e $37,79 \%)$ e das de competência $(13,40 \%$ e $27,55 \%$; e

- segundo os autores CLARK (1986); KRATZ (1981); SNOW-ANTLE (1984), delineia-se um perfil do enfermeiro caracterizado por uma imagem positiva, carregada de aspectos fundamentalmente humanitários.

No entanto, notamos através dos valores obtidos nos estudos anteriormente apresentados, que os predicados de competência vêm sendo significativamente inclú́dos na atribuição de predicados.ao enfermeiro.

Ao analisar-se os resultados das Escolas separadamente, observa-se que os alunos da Escola A citaram em maior freqüência e de forma homogênea as características de competência e humanitárias $(14,96 \%$ e $14,71 \%$ respectivamente). Já os alunos da Escola B, também citaram essas mesmas características em maior frequiência, embora priorizando 
as humanitárias $(23,62 \%)$ em relação às de competência $(12,60 \%)$.

Essa diferença poderia estar associada às variações de faixa etária encontradas entre os alunos na Escola A e que não ocorreram na Escola B. Indivfduos inseridos em uma faixa etária mais elevada geralmente apresentam maiores níveis de maturidade e encargos sociais que possivelmente os levaram a experiências de trabalho anteriores. Estes fatores podem ter caracterizado uma valorização mais eqüitativa por parte dos estudantes da Escola A, entre o "humano" e o "competente" do enfermeiro, ressaltando também como aspectos profissionais, a projeção ou "status" social e a responsabilidade.

As atividades atribuídas ao enfermeiro e classificadas como assistenciais, englobaram os itens: integral, expressiva ou básica e instrumental ou técnica. Estes dois últimos agrupamentos foram baseados na classificação utilizada por KAMIYANA (1972).

Verificou-se que os estudantes atribuíram um total de 65 atividades ao enfermeiro, perfazendo a média de 1,8 citações por aluno. Considerando-se esta média em relação àquela obtida das respostas da questão 2 (3,5 menções por aluno), constata-se um número bem maior de características do que atividades apontadas pelos alunos. Estes dados vêm corroborar os resultados apresentados na Tabela 1, quando a imagem do enfermeiro foi delineada predominantemente por características pessoais.

Os dados mostram que as atividades assistenciais atribuídas ao enfermeiro pelos alunos, foram coerentes com a imagem humanitária já discutida anteriormente.

As atividades citadas foram, em sua maioria, de caráter assistencial $(56,93 \%)$, distribuindo-se homogeneamente nas duas Escolas $(24,62 \%$ na Escola A e $32,31 \%$ na Escola B). Destas atividades assistenciais, houve predomínio de respostas relacionadas ao cuidado integral.

O cuidado integral tem sido enfatizado nos últimos anos, como uma das bases da Enfermagem e tem se constiturdo em objetivo do ensino nos currículos dos cursos de graduação em Enfermagem (SNOW-ANTLE, 1984).

Considera-se de grande importância que o cuidado tenha sido uma atividade citada, com predominância, como uma das características da assistência prestada pelo enfermeiro. Isto parece indicar que têm ocorrido mudanças positivas na imagem do enfermeiro junto ao público e que estas têm influenciado a opinião dos estudantes. Evidencia-se assim, a necessidade de que os educadores da Enfermagem trabalhem no sentido de enfatizar cada vez mais o cuidado integral do paciente, estimulando e favorecendo a incorporação deste conceito pelo aluno, em sua conduta profissional. Talvez seja esta uma forma de se obter avanços no sentido de se projetar uma imagem profissional mais positiva.

Quanto às atividades administrativas, foram apontadas em $23,07 \%$ das respostas, em $2{ }^{\circ}$ lugar de freqüência em ambas as Escolas $(15,38 \%$ na Escola A e $7,69 \%$ na Escola B).

Essas atividades administrativas têm sido hipertrofiadas dentro da Enfermagem, não como administração de assistência, mas com ênf ase nos aspectos burocráticos. Isto tem influído negativamente na imagem pública do enfermeiro (SOUSA et alii, 1986). SNOW-ANTLE (1984), revela-nos em seu estudo, que $42 \%$ da população pesquisada considera que o enfermeiro deveria gastar mais tempo ao lado do leito do paciente e estar mais envolvido no cuidado direto deste.

O estereótipo do enfermeiro como "'auxiliar do médico" " parece ainda estar fortemente arraigado na população $(3,19 \%)$, o que se vê reforçado, quando se verificam respostas dessa natureza por parte dos alunos. Em níveis de 12,31\%. SNOW-ANTLE (1984) constatou também que $80 \%$ da população que estudou, tem a impressão de que as enfermeiras realizam algum trabalho desenvolvido por médicos. Ainda em relação a este aspecto COLLINS \& JOEL apud CASTRO (1984), em estudos da imagem da enfermeira entre estudantes norte-americanos, obteve respostas acerca das atividades de enfermeira como alguém que "cumpre ordens médicas".

Observa-se que este aspecto da enfermeira tida como "auxiliar do médico", ainda está bem presente quando se vê que na sociedade prevalecem os valores definidos pelos homens e, portanto, inteligência, recursos matemáticos e tecnológicos parecem ser menos exigidos da mulher e da enfermeira (WATSON, 1982).

Este aspecto é também reforçado pela população, ao considerar que a formação do médico e do enfermeiro ocorrem num "continuum", havendo uma menor exigência e uma menor duração do curso de Enfermagem em relação ao curso de medicina.

Os locais de trabalho do enfermeiro mais indicados pelos alunos das duas escolas, foram aqueles que incluíram o atendimento do paciente em regime de internação $(41,67 \%)$ e ambulatorial $(31,67 \%)$. 0 mesmo ocorreu nas respostas por Escola: A $(19,17 \%$ e $12,50 \%$, respectivamente) e B $(22,50 \%$ e $19,17 \%$, respectivamente).

Esses locais mais citados coincidem com aqueles onde mais comumente os enfermeiros realmente atuam, além de serem mais difundidos pelos meios de comunicação e portanto, mais conhecidos pela população em geral.

No entanto, é importante evidenciar que houve algumas citações de indústrias e consultórios particulares, como campos de atuação profissional a nível ambulatorial, ambos pouco conhecidos, sendo que os consultórios particulares são menos valorizados como atividade liberal.

Outros locais ainda pouco conhecidos, também foram citados, embora em baixa freqüência como: creches, escolas, domicńlio, asilos, clubes e laboratórios. 
Desta feita, é importante salientar que mesmo os alunos ingressantes vêm com uma visão um pouco mais abrangente e até inovadora, em relação às possibilidades de um mercado de trabalho mais ampliado.

A imagem que os estudantes atribuíram ao enfermeiro, foi influenciada pelos quatro fatores: experiências vivenciadas em situações de doença $(30,19 \%)$, relacionamento com familiares ou amigos enfermeiros $(26,41 \%)$, antecedentes de trabalho no campo de saúde $(18,87 \%)$ e meios de comunicação (16,98\%). Na Escola B, as influências ocorreram de maneira mais homogênea do que na Escola A, onde as respostas dos alunos polarizaram-se para as experiências vivenciadas em situações de doença $(18,87 \%)$ e relacionamento com familiares ou amigos enfermeiros $(15,09 \%)$.

Muitas enfermeiras consideram que a opinião pública acerca de enfermagem é freqüentemente influenciada pelos meios de comunicação, o que em nosso estudo, foi citado apenas em 4. maior freqüência $(16,98 \%)$.

SNOW-ANTLE (1984), também revela em seu estudo que somente $10 \%$ dos respondentes admitiram a influência da TV, jornais e revistas na formação da imagem profissional do enfermeiro. Ainda nesse trabalho, a grande maioria dos individuos (77\%) afirmou que essa imagem derivou-se mais de suas experiências em hospitais, em concordância com os resultados obtidos no presente trabalho $(30,19 \%$ das respostas).

Quanto à influência da imagem do enfermeiro na escolha profissional feita pelos estudantes verificou-se:

- Influências positivas: incluíram-se neste item as respostas que denotaram identificação com a imagem positiva do enfermeiro (prestar cuidados, ajudar individuos, profissão gratificante, humanitária).

- Influência negativa: a imagem do enfermeiro abalou sua convicção da opção pela enfermagem.

- Influências ausentes: a imagem não influenciou sua opção pela enfermagem (falta de outra opção; bom mercado de trabalho).

Esta questão não foi respondida por 5 estudantes, sendo 4 da Escola A e 1 da Escola B.

Constata-se que a escolha profissional feita pelos estudantes das duas escolas foi influenciada positivamente pela imagem do enfermeiro $(64,51 \%)$.

Analisando-se os dados comparativamente, verifica-se que houve predominância de respostas indicativas de influências positivas na Escola B $(45,16 \%)$ com relação à Escola A $(19,35 \%)$. Esta mesma Escola apresentou, por sua vez, maior fre- qüência de respostas indicativas de ausência da influência da imagem do enfermeiro na escolha da profissão $(32,26 \%)$.

As influências positivas citadas pelos alunos, relacionaram-se principalmente à identificação com a imagem positiva do enfermeiro, no que tange à "prestação de cuidados", "ajuda às pessoas" e "profissão humanitária". Essa imagem positiva do enfermeiro foi caracterizada anteriormente, através dos predicados humanitários e das atividades assistenciais, indicados em elevadas freqüências pelos estudantes de ambas as Escolas.

Estudos realizados por ARCURI et alii (1983) e MORAIS \& RUSSO apud ARCURI et alii (1983), identificaram como o 2 . . fator mais freqüente que influenciou os alunos na opção pela enfermagem, o “desejo de ajudar pessoas”. Além disso, vários depoimentos publicados por estudantes norte-americanos, mostram que uma das atrações da profissão é exatamente o trabalho junto às pessoas (SELBY, 1984; 1985; WATSON, 1982).

Tanto o "desejo de ajudar pessoas" quanto a "atração pelo trabalho junto às pessoas", constituem características que neste estudo estão contidas nos predicados humanitários e nas atividades assistenciais, que por sua vez compuseram significativamente a mesma imagem positiva do enfermeiro, que influenciou os alunos na escolha profissional.

Cabe ressaltar que dentre os estudantes (Escola A) que afirmaram não terem sof rido influências da imagem do enfermeiro na escolha da profissão, a maioria está cursando Enfermagem por não ter tido acesso às suas opções profissionais.

Considerando-se portanto, os seguintes dados derivados das respostas dos alunos da Escola A:

- que a ausência de influência caracterizou-se por uma não opção original pela Enfermagem;

- que os maiores índices de Contradição Interna (CI) foram constatados nas respostas do mesmo grupo, em que também ocorreu elevada ausência de influência da imagem do enfermeiro na escolha profissional (Escola A) e que um elevado índice de CI pode significar que uma determinada palavra é afetivamente controvertida ou conflitual entre os sujeitos de um mesmo grupo, pode-se dizer que esses alunos tinham uma imagem negativa da enfermagem através do significado negativo das palavras enfermeiro e enfermeira, e que portanto, teriam sido responsáveis por esses níveis de Contradição Interna (C.I.) (LANE, 1982; 1972).

Todas essas considerações denotam de maneira concludente e enfática, mais uma vez, que a imagem é um fator determinante na opção profissional.

\section{CONCLUSŌES}

O estudo sobre a imagem do enfermeiro e da enfermeira percebida pelos alunos ingressantes em duas Escolas de Enfermagem da Cidade de São Paulo, permitiu as conclusões que se seguem: 
- A imagem da(o) enfermeira(o) foi considerada positiva.

- A enfermeira e o enfermeiro foram percebidos, em diferentes intensidades, como bons, fortes, estáveis, rápidos, simples, grandes e úteis.

- A imagem do enfermeiro atriburda pelos estudantes foi composta, predominantemente, por predicados pessoais $(91,75 \%)$.

- Os predicados pessoais humanitários predominam entre as respostas dos estudantes, quanto à imagem $(32,99 \%)$ e à caracterização do enfermeiro $(37,39 \%)$. Nas características atribuídas ao enfermeiro também sobressaíram-se as de competência $(27,56 \%)$.

- As atividades atriburdas ao enfermeiro foram em sua maioria assistenciais $(56,93 \%)$, seguidas das administrativas $(20,07 \%)$ e auxiliares do médico $(12,31 \%)$. Dentre as atividades assistenciais, as mais citadas foram as referentes ao cuidado integral.

- Os locais de trabalho do enfermeiro indicados em maiores freqüências foram: com regime de internação $(41,66 \%)$ e com regime de atendimento ambulatorial $(31,67 \%)$.

- A formação da imagem do enfermeiro apresentada pelos estudantes, foi influenciada por: experiências vivenciadas em situações de doença $(30,19 \%)$ e relacionamento com familiares ou amigos enfermeiros $(26,41 \%)$, seguidas de antecedentes de trabalho no campo da saúde $(18,87 \%)$ e meios de comunicação (16,98\%).

- A escolha profissional feita pelos estudantes foi influenciada positivamente pela imagem do enfermeiro $(64,51 \%)$. A escolha profissional não sofreu influências da imagem do enfermeiro, num indice de respostas de $32,26 \%$.

- Não houve diferença significativa entre os significados das palavras enfermeira e enfermeiro, quanto a qualquer um dos fatores estudados, quando comparados entre as duas Escolas.

- Houve diferença significativa ao nível de $5 \%$ para a palavra enfermeiro, em relação ao fator IV (Agilidade), independentemente da Escola de origem.

- Os estudantes da Escola A atribuíram ao enfermeiro, de forma predominante e homogênea, as características humanitária e de competência $(14,17 \%$ e $14,96 \%)$ respectivamente). Diferentemente, na Escola B, as características humanitárias obtiveram um índice mais elevado $(23,62 \%)$ em relação às demais características.

- Os alunos da Escola A indicaram ausência de influências da imagem do enfermeiro na escolha profissional em $32,26 \%$ das respostas, comparativamente às influências positivas $(19,35 \%)$. Os alunos da Escola B apontaram, predominantemente, as influências positivas nas suas opções profissionais. Não houve, nesta Escola, resposta indicativa de ausência de influência.

\section{CONSIDERAÇÓES FINAIS E RECOMEN- DAÇŌES}

A imagem é fundamental no desenvolvimento profissional e está diretamente relacionada ao poder, autonomia e ao status da profissão. Assim sendo, pode-se afirmar que a projeção de uma imagem negativa dificulta o desenvolvimento da profissão e o seu reconhecimento por parte da sociedade. $O$ que as pessoas pensam do profissional é tão importante quanto aquilo que ele realmente é.

O estereótipo interfere na opinião das pessoas acerca da prof issão influenciando na escolha profissional e afetando a quantidade e a qualidade de alunos que ingressam nas Escolas de Enfermagem, como se tem observado atualmente. Desta forma, evidencia-se a importância da imagem tanto para uma maior valorização na profissão, como para a sua continuidade.

O auto-conceito e auto-estima, são alguns fatores determinantes da imagem profissional. Portanto, há necessidade de que as(os) enfermeiras(os) sejam estimulados a desenvolverem seu auto-conceito e sua auto-estima, buscando atingi-los em níveis elevados, a fim de embasar mudanças significativas na imagem profissional, tomando-a mais positiva. Estes fatores precisam ser trabalhados a nível individual, principalmente pelos educadores das Escolas de Enfermagem, pelos enfermeiros, estudantes e pelos próprios docentes.

Acredita-se que parte das distorções existentes na atual imagem pública do enfermeiro, tenham como ponto de partida, problemas de auto-conceito e auto-estima, ainda não resolvidos pelos próprios profissionais, o que pode acarretar um baixo grau de auto-realização.

Para propagar e fomentar uma imagem positiva na profissão Enfermagem, o papel dos educadores desta área é de vital importância, devendo-se começar a trabalhar e a desenvolver o auto-conceito e a auto-estima nos alunos ingressantes, tentando-se estimular neles próprios uma crença básica em si mesmos e transmitindo-lhes a importância da contribuição individual para a formação de uma imagem real e duradoura.

Pelos resultados obtidos neste estudo, pode-se dizer que parece estar se processando uma mudança positiva na imagem do enfermeiro tida pelo aluno ingressante, o que por sua vez, pode estar refletindo a existência de modificações na imagem pública, já que este aluno, ainda não tem um elevado grau de envolvimento com a profissão, o que poderia influenciar na formação da sua imagem.

As características de competência e humanitarismo foram mencionadas neste trabalho com consideráveis freqüências pelos estudantes ingressantes, o que parece indicar uma visão mais profissional da Enfermagem. Uma das maneiras de se projetar uma imagem mais real e duradoura, é por meio do em- 
penho no desenvolvimento da competência, porém, não abandonando as características humanitárias, pois ambas são necessárias para que se mantenha uma imagem que reflita a realidade da profissão.

Os enfermeiros esperam ser apreciados e respeitados, reconhecidos pela sua capacidade, consultados sobre suas áreas de responsabilidade e participarem na tomada de decisões (SMITH \& NORONE, 1986).

É possível que isto ocorra efetivamente, a partir do momento em que demonstrarem sua competência, fazendo-se presentes e ocupando seu espaço. Desta forma estarão promovendo mudanças na sua imagem profissional, conquistando autonomia e poder, e, ao mesmo tempo consolidando a Enfermagem como uma profissão.

Segundo MARSH (1983), a mídia não pode modificar a imagem de uma profissão. Isto reforça a idéia de que a transformação da imagem da(o) enfermeira(o) compreende a participação de todos os profissionais desta área, tanto daqueles envolvidos com a prática, quanto aos professores e alunos, num esforço conjunto para a projeção de uma imagem mais realista.

\section{REFERÊNCIAS BIBLIOGRÁFICAS}

1 ALMEIDA, M.C.P. \& ROCHA, J. S. Y. O saber de Enfermagem e sua dimensão prática. São Paulo, Cortez, 1988.p.37-39.

2 ARCURI, E.A.M. et a lii. Fatores que influenciaram alunos ingressantes na Escola de Enfermagem da USP, em 1981, na escolha da enfermagem como opção profissional. Rev. Esc. Enf. USP, São Paulo, 17 (1):5-19, jan./abr. 1983.

3 AUSTIN, J.K. et alii. Crosscultural comparison on nursing inage. Int. J. Nurs. Stud., Oxford, 22(3):231-239, Aug. 1985.

4 BAKER, H.K. \& MORGAN, P.I. Building a professional image: gaining awareness. Superv. Manage, Saranac Lake, 30(7):15-22, July 1985 .

5 BARDIN, L. Análise de Conteúdo. Lisboa, Edições 70, 1977. cap 2, p. 155-68.

6 CABRAL, A. \& NICK, E. Dicionário técnico de psicologia. São Paulo, Cultrix, 1974, 406 p.

7 CASTRO, I.B. et alii. Modificação na imagem da enfermeira percebida pelos estudantes, durante o Curso de Graduação de Enfermagem. Rev. Bras. Enf. Brasília, 27 (2):180-205 , abr./jun.1974.

8 CLARK, M.D. The historical basis nursing's troubled selt image. AAOHN J.Atlanta, 34 (4): 160-70, Apr. 1986.

9 DORSCH, F. Dicionário de Psicologia. Barcelona, Herder, 1976. $143 \mathrm{p}$.
10 FISHBEIN, M.\& AJZEN. Belief, Attitud, intention and behavior: an introduction to theory and research. Meulo-Park, Addison-Wesley, 1975, cap. 3, p. 73-79.

11 HAMMER, R.M. \& TUFTS, M.A. Nurse's self-imagem responsability of the nursing education. J. Nurs. Educ., Thorafare, 24 (7): 280-3, Sept. 1985.

12 HORTA, W.A. \& KAMNEBLEY, Z. M. Avaliação da dor em pacientes submetidos à cirurgia da tireóide pela aplicação do método da Escala Diferencial Semântica de Osgood. Rev. Bras. Enf., Brasilia 28 (2): 43-53, abr./ju. 1975.

13 HOTT, R.. The public imagem of the nurse of the get-well card-to see ourselves as others see us. Imprint, New York, 31 (1): 45-48. Feb./ Mar. 1984.

14 KAMIYAMA, Y. O doente hospitalizado e sua percepção quanto a prioridade de seus problemas. São Paulo, 1972. 111 p. (Tese de Doutoramento - Escola de Enfermagem da USP).

15 KRATZ, C. Nurses and herosism. Nurs. Times, London, 77 (36): 1634-5, Sept., 1981 .

16 KUENZER, M. Nurse's image: early perception. Imprint, New York, 32(1): 61-63, Feb./Mar. 1985.

17 LANE, S.T.M. O mundo através das palavras. São Paulo, Editora PUC, 1982. p. 119-185. (Cademos PUC-Psicologia, 15).

18 LANE, S.T.M. Significado psicológico de palavras em diferentes grupos sócio-culturais. Rev. Psic. Normal Patol., São Paulo, 18 (3/4): 3-152, jul./dez. 1972.

19 MC FARLANE, J. Nursing-images and reality. Nurs. Mirror, Sussex, 160 (1): 16-18, Jan 2, 1985.

20 MARSH, L.C. Image-whose is it? Ky.Nurse, Kentucky, 31 (3):2, May/June 1983.

21 SELBY, Y.L. Career variety, opportunity attract students. Am.Nurs., Kansas City, 16 (9): 1,7,22, Oct. 1984.

22 Range of opportunities attracts students to careers in nursing. Am.Nurs., Kansas City 17(9): 1,7,10 Oct 1985.

23 SIEGEL, S. Estatística não paramétrica. São Paulo, Mc Graw Hill, 1975. 350 p.

24 SMITH, B.A. \& NERONE, B.J. Marketing a profitable nursing image recongnizing image is power. Imprint. New York, 33 (1): 26-30, Feb./Mar. 1986.

25 SNOW-ANTLE, S. The image across the Atlantic. Nurs. Times, London, 80 (2): 54-6, Jan. 11, 1984.

26 SOUSA, R.M.C. et alii. Enfermagem: uma abordagem conceitual. Rev. Esc. Enf. USP, São Paulo, 20 (3): 229-35, dez. 1986.

27 TIFFANY, R. Striving to be more than Cinderellas. Nurs. Mirror, Sussex, 153 (25): 28-30, Dec. 16, 1981.

28 WATSON, C. Safe, obedient and quiet. Nurs. Mirror, Sussex, 154 (16): 18-9, Apr. 21, 1982. 